\title{
Prevalence and risk factors associated with asymptomatic malaria among school children: repeated cross-sectional surveys of school children in two ecological zones in Ghana
}

\author{
B. A. Mensah', J. L. Myers-Hansen ${ }^{1,2}$, E. Obeng Amoako ${ }^{1}$, M. Opoku ${ }^{1,2}$, B. K. Abuaku ${ }^{1+}$ and A. Ghansah ${ }^{1,2^{*+}}$
}

\begin{abstract}
Background: Asymptomatic Plasmodium infections significantly drive malaria transmission and impact control and elimination strategies, but are largely uncharacterized. We investigated the prevalence and risk factors of asymptomatic malaria infections to inform malaria control strategies in Ghana.

Method: Five cross-sectional surveys were conducted at the end of the peak transmission season (AugustSeptember) on 4892 school children aged between 6 and 14 years in two distinct ecological settings in Ghana between 2013 and 2017. The study sites were Begoro (forest ecology) and Cape Coast (coastal ecology). The children were screened for malaria parasites by microscopic examination of Giemsa-stained thin and thick blood films. Hemoglobin levels were measured using the Hemocue HB analyzer. In addition, height was measured and the height-for-age $z$-scores estimated from the reference population defined by WHO to determine children who were stunted. Proportions of categorical and means of continuous variables were compared using Chi-square test and Student's t-test respectively, and multivariable logistic regression was done to assess risk factors associated with asymptomatic infections.

Results: The overall prevalence of asymptomatic malaria in the school children was higher in Begoro compared to Cape Coast (27\% (95\% Cl: 17, 24\%) vs. 24\% (95\% Cl: 17, 24\%), $p$ value $=0.04)$. The study recorded three species of Plasmodium (Plasmodia falciparum, malariae, and ovale) in both sites. Plasmodium falciparum was the predominant species, accounting for about $85 \%$ of infections in both study sites. The asymptomatic school children were more likely to be anaemic $(\mathrm{OR}=2.01, p$ value $<0.001)$ and stunted in growth $(\mathrm{OR}=1.46, p$ value $<0.001)$. Males carried more asymptomatic infection than females $(\mathrm{OR}=1.18, p$ value $=0.015)$. School children aged $12-14$ years had more asymptomatic infections than those aged $6-8$ years $(O R=1.28, p$ value $=0.005)$.
\end{abstract}

\footnotetext{
* Correspondence: Aghansah@noguchi.ug.edu.gh

${ }^{+}$B. K. Abuaku and A. Ghansah contributed equally to this work. 'Department of Epidemiology, College of Health Sciences, Noguchi Memorial Institute for Medical Research, University of Ghana, Accra, Ghana ${ }^{2}$ Department of Parasitology, College of Health Sciences, Noguchi Memorial Institute for Medical Research, University of Ghana, Accra, Ghana
}

C C The Author(s). 2021 Open Access This article is licensed under a Creative Commons Attribution 4.0 International License, which permits use, sharing, adaptation, distribution and reproduction in any medium or format, as long as you give appropriate credit to the original author(s) and the source, provide a link to the Creative Commons licence, and indicate if changes were made. The images or other third party material in this article are included in the article's Creative Commons licence, unless indicated otherwise in a credit line to the material. If material is not included in the article's Creative Commons licence and your intended use is not permitted by statutory regulation or exceeds the permitted use, you will need to obtain permission directly from the copyright holder. To view a copy of this licence, visit http://creativecommons.org/licenses/by/4.0/. The Creative Commons Public Domain Dedication waiver (http://creativecommons.org/publicdomain/zero/1.0/) applies to the data made available in this article, unless otherwise stated in a credit line to the data. 
Conclusion: There is a considerable burden of asymptomatic malaria in the two regions of Ghana, which is associated with males, older children, anaemia, and stunted growth in children, and may have implications for malaria control and elimination strategies in Ghana.

Keywords: Asymptomatic infection, Plasmodium, Risk factors, Malaria burden, Ghana

\section{Background}

Malaria is still one of the leading global public health concerns. Although there was a decline in malaria morbidity and mortality worldwide in 2018, sub-Saharan Africa saw an increase of about one million cases that same year [1]. Economic data from WHO malaria report shows that, in 2018, the WHO African Region spend nearly 3 quarter of the US\$ 2.7 billion invested in malaria on case management and prevention [1] and cost up to $1.3 \%$ of GDP in Africa [2]. In addition, malaria is a major cause of absenteeism among school children in endemic countries [3-5].

Ghana is a malaria-endemic country and falls within the top 15 highest-burden countries [1]. In 2018, Ghana's disease burden contributed to about $3 \%$ of the global malaria cases recorded [1] and 33\% of all the national Out-Patient Department (OPD) cases recorded in 2017 [6]. Pregnant women and children under 5 years are the most affected by the disease because they have low immunity and malaria can cause anaemia in both groups resulting in debilitating outcomes like cerebral malaria and death [1].

Plasmodium falciparum infections may result in severe, uncomplicated or asymptomatic malaria. There is a wealth of studies and data on uncomplicated and severe malaria because they are the drivers of malaria-related morbidity and mortality respectively. Comparatively, asymptomatic malaria infection is understudied and remain a challenge to malaria control due to its effect on transmission dynamics [7].

Asymptomatic malaria, is defined as the presence of parasites in people and an absence of malaria-related symptoms such as temperature $>37.5^{\circ} \mathrm{C}$. Asymptomatic malaria occurs as a result of continuous exposure to malaria infections, leading to the acquisition of partial immunity against complications such as cerebral malaria and the accumulation of the "reservoir of infection" [8]. $P$. falciparum infection has been shown to persist asymptomatically in semi-immune individuals for more than 18 months especially in older children [7] making them important reservoirs for sustaining malaria transmission in regions of low and high malaria endemicity [9-15]. The asymptomatic reservoir contributes to gametocyte carriage (the stage of the life-cycle of the parasites that cause mosquito transmission) to drive and maintain transmission by the local mosquito vectors [7, 16]. Some findings suggest that asymptomatic carriers are more infectious than symptomatics $[9,17,18]$ as they contribute to infectiousness for longer periods of time when they are not treated [19]. Aside from it being a reservoir for malaria transmission, asymptomatic carriage causes several other challenges including but not limited to anaemia, stunting, and cognitive impairment in school children [20, 21].

Like most malaria control programs, control efforts in Ghana gravitate towards a system, which identifies, treats, and reports people with malaria presenting at health care facilities giving little attention to asymptomatic cases in the community. However, through seasonal malaria chemoprevention and intermittent preventive treatments, a subset of asymptomatic infections is treated but not tracked. For successful malaria elimination, however, the full complement of the burden of infection, including the asymptomatic reservoir should be the focus. Thus, the asymptomatic carrier must be actively characterized [22].

To better understand the asymptomatic burden in Ghana, we leveraged repeated school-based crosssectional surveys on the impact of parasite diversity on the evolution of drug resistance. We characterized the asymptomatic burden and its associated risk factors in two sites in Ghana with varying malaria endemicities. We show that the asymptomatic burden is significant in both sites and are influenced by risk factors such as age, anaemia, and stunted growth in children.

\section{Methods \\ Study design, setting, population and ethics approval}

Repeated cross-sectional surveys were conducted in Cape Coast and Begoro for five consecutive years (2013-2017). Cape Coast is in the coastal savanna ecological zone of Ghana where malaria transmission is low to moderate and perennial. Begoro is situated in the forest ecological zone of Ghana, where malaria transmission is high and perennial. The detailed description of these study sites has been described elsewhere [23]. The study participants included children aged between 6 and 14 years attending selected schools in the catchment areas of the study, whose parents/guardians gave informed consent to be part of the study and who also assented if aged 12 to 14 . Three schools were randomly selected in each ecological zone and the children aged between 6 years and 14 years screened for malaria infection using microscopy. Children who were on malaria 
medication within 2 weeks prior to recruitment into the study and tested positive were excluded. The study was conducted following the latest Declaration of Helsinki and Good Clinical Practice (GCP). The protocol was approved by the ethics review board of Noguchi Memorial Institute for Medical Research, University of Ghana.

\section{Sample size and power}

The study primarily compared the prevalence of asymptomatic malaria in the two study sites. A minimum sample size of 1933 per study site provides $80 \%$ power to determine as low as a $4 \%$ difference in asymptomatic malaria between study sites at a 95\% confidence level and $5 \%$ precision.

\section{Sampling method}

The list of all schools in the catchment areas of this study was obtained from the municipal education office and three schools randomly selected for each study site. All the school children aged 6 to 14 years from the selected schools, whose parents gave informed consent and assented if aged 12 to 14 were screened.

\section{Sample collection and diagnostic methods}

Blood smears were prepared for each participant in the study. Two slides per participant were obtained: one with a thick smear and the other with both thick and thin smears. The thick smear slide was stained rapidly (10\% Giemsa for 10-15 min) for initial screening, while the thick and thin smear slides were retained for subsequent quantification of the parasites if the participant tested positive. The parasite density was estimated, by counting the number of asexual parasites against 200 WBC with a hand tally counter. Parasite density was calculated as follows: Parasite density $($ per $\mu \mathrm{l})=($ number of parasites counted $\div$ number of leukocytes counted) $\times$ 8000. Haemoglobin levels were determined for all patients using a portable HemoCue ${ }^{\oplus} \mathrm{Hb} 301$ Analyzer (HemoCue ${ }^{\oplus}$ AB, Ängelholm, Sweden). The body weight, height, and axillary temperature were also measured. Children who tested positive for malaria and had fever were treated with artesunate amodiaquine as recommended by the national malaria control program (NMPC).

\section{Definition of terms}

- Asymptomatic malaria: the presence of parasites in peripheral thick blood smears, an axillary temperature $<37.5^{\circ} \mathrm{C}$, and an absence of malariarelated symptoms [7].

- Anaemia: Anaemia in children was defined as having haemoglobin $(\mathrm{Hb})<11 \mathrm{~g} / \mathrm{dL}$
- Stunting in children is defined as height-for-age zscore (HAZ) below negative two standard deviations from the median of the reference population, using the WHO Child Growth Standards

\section{Statistical analysis}

The variables hemoglobin and height-for-age z-scores were categorized into binary variables. Height-for-age zscores were categorized as "stunted" (z-score less than or equal to $-2 \mathrm{SD}$ ) and "not stunted" (z-score greater than - $2 \mathrm{SD}$ ), haemoglobin was categorized as anaemic $(\mathrm{HB}<11 \mathrm{~g} / \mathrm{dl})$ and "non-anaemic" $(\mathrm{HB} \geq 11 \mathrm{~g} / \mathrm{dl})$. All statistical analyses were performed using the statistical software STATA version 12. Continuous data were summarized into means and standard deviations (SD) (age, weight, height, parasite density, haemoglobin, and axillary temperature) and categorical data into proportions for descriptive analysis. Parasite density which is not normally distributed was log-transformed and the geometric mean calculated. Means were compared between study sites using Student's t-test/Mann Whitney rank test, while proportions were compared using Pearson's Chi-square tests/Fisher exact test. Trends of asymptomatic malaria over the study period were compared using the Cochrane Armitage test of trends. Univariate analysis to determine potential risk factors of asymptomatic malaria was performed using the Student's t-test/Mann Whitney rank test for continuous variables and Pearson Chi-square test/Fisher exact test for categorical variables. The association between asymptomatic malaria and anaemia, stunting, gender, age, and study site was explored using multivariable logistic regression and the odds ratio and confidence intervals recorded. The significance level was set at $p<0.05$ for all tests.

\section{Results}

Baseline characteristics of study participants and the prevalence of asymptomatic malaria

A total of 4892 school children aged between 6 and 14 years, were screened; 2394 from Begoro and 2498 from Cape Coast over the five-year study period. Of these, $52.9 \%$ were females, $13.9 \%$ were anaemic, $11.1 \%$ had stunted growth, mean age was 10.3 years, and the geometric mean of parasite density was 289.4. Children in the Cape Coast municipal catchment area were more anaemic compared to those recruited from Begoro (17\% vs $10 \%$ respectively, $p$ value $<0.001)$. Also, the proportion of children from Cape Coast who were stunted was higher than observed in Begoro (14.5\% vs $7.6 \%$ respectively, $p$ value $<0.001)$. With the exception of 2014 , the prevalence of asymptomatic malaria was always higher in Begoro compared to Cape Coast. The overall prevalence of asymptomatic malaria in Begoro was higher than in Cape Coast $(27 \%$ vs $24 \%, p$ value $=0.04$ Table 1$)$, though 
Table 1 Baseline characteristics of study participants by ecological zones

\begin{tabular}{|c|c|c|c|c|}
\hline \multirow[t]{2}{*}{ Characteristics } & \multirow[t]{2}{*}{ Total } & \multicolumn{2}{|l|}{ Ecological zone } & \multirow[b]{2}{*}{$p$ value } \\
\hline & & Forest (FZ) & Coastal (CSZ) & \\
\hline \multicolumn{5}{|l|}{ Prevalence of malaria $\mathrm{n} / \mathrm{N}(\%)$} \\
\hline 2013 & 273/1037 (26.3) & $127 / 478(26.6)$ & $146 / 559(26.1)$ & 0.869 \\
\hline 2014 & 161/781 (20.6) & $62 / 382(16.2)$ & $99 / 399(24.8)$ & 0.003 \\
\hline 2015 & 261/935 (27.9) & $142 / 452(31.42)$ & 119/483 (24.6) & 0.021 \\
\hline 2016 & $241 / 1027(23.5)$ & $127 / 525(24.2)$ & $114 / 502(22.47)$ & 0.576 \\
\hline 2017 & $300 / 1112(27.0)$ & 178/557 (32.0) & $122 / 555(22.0)$ & $<0.001$ \\
\hline Total & 1236/4892 (25.3) & 636/2394 (26.6) & 600/2498 (24.0) & 0.040 \\
\hline Mean age in years (SD) & $10.3(2.4)$ & $10.3(2.3)$ & $10.3(2.5)$ & 0.5258 \\
\hline Age group $n(\%)$ in years & & & & 0.016 \\
\hline Aged 6 to 8 years & $1247(25.5)$ & $602(25.2)$ & $645(25.9)$ & \\
\hline Aged 9 to 11 years & $1862(38.1)$ & $959(40.1)$ & $903(36.2)$ & \\
\hline Aged 12 to 14 years & $1779(36.4)$ & $833(34.8)$ & $946(37.9)$ & \\
\hline Gender n (\%) & & & & 0.148 \\
\hline Female & $2589(52.9)$ & $1292(53.9)$ & $1296(51.9)$ & \\
\hline Male & $2303(47.1)$ & $1103(46.1)$ & $1202(48.1)$ & \\
\hline Anaemia n/N (\%) & & & & $<0.001$ \\
\hline Normal & $4160 / 4831(86.1)$ & 2139/2390 (89.5) & 2021/2441 (82.8) & \\
\hline Anaemic & $671 / 4831(13.9)$ & $251 / 2390(10.5)$ & $420 / 2441(17.2)$ & \\
\hline Stunted growth & & & & $<0.001$ \\
\hline Normal & $4349(88.9)$ & $2213(92.4)$ & $2136(85.5)$ & \\
\hline Stunted & $545(11.1)$ & $182(7.6)$ & $363(14.5)$ & \\
\hline Geometric mean parasitaemia/ $\mu \mathrm{L}$ & 289.4 & 289.9 & 295.0 & 0.9331 \\
\hline Parasitaemia range & $(13.79,95,400)$ & $(13.8,65,910.5)$ & $(8.0,95,400)$ & \\
\hline
\end{tabular}

there was no significant trend over the five-year period of the study. Three out of the five human Plasmodium species were found in both study sites (Fig. 1). These were P. falciparum (PF, 82 and $85.6 \%$ in Begoro and Cape Coast respectively), P. malariae (PM, 14 and 10\% in Begoro and Cape Coast respectively), $P$. ovale (PO, < $1 \%$ in both Begoro and Cape Coast). Cape Coast had 3\% mixed infections of PF, PM, and $0.3 \%$ of $\mathrm{PF}, \mathrm{PO}$, while, Begoro had $2 \%$ of PF, PM but no mixed infection of PF, PO. (Fig. 2 below).

Determinants of asymptomatic malaria in school children Table 2 shows the determinants of asymptomatic malaria in school-aged children in the two study sites in Ghana. All five risk factors considered: gender, age, anaemia, study site, and stunting were associated with asymptomatic malaria. Asymptomatic carriage was higher in males compared to females $(28 \%$ vs. $23 \% p$ value $=0.001$ ). In comparison with the other age groupings, the older children (aged between 12 and 14 years) were more asymptomatically infected ( $27 \%$ vs. 25 and $23 \%, p$ value $=0.019$ ). The prevalence of asymptomatic malaria was higher in anaemic children compared to the non-anaemic children $(38 \%$ vs. $23 \%, p$ value $<0.001)$. Prevalence of asymptomatic malaria was higher in children who were stunted (34\%) compared to those who were not ( $34 \%$ vs. $24 \%, p$ value $<0.001)$. Children living in the Begoro catchment area were more likely to be asymptotic carriers than those living in Cape Coast (26.6\% vs. $24 \%, p$ value $<0.04)$.

\section{Multivariable analysis of potential risk factors of asymptomatic malaria}

A logistic regression model was used to explore the associations between the potential risk factors and asymptomatic malaria. After adjusting for confounders (age, stunted growth, anaemia and study site), being male increased the odds of asymptomatic malaria by $18 \%$ (OR = $1.18,95 \% \mathrm{CI}=1.03,1.35, p$ value $=0.015)$. The odds of asymptomatic malaria in the 12-14 years age group was 1.28 times higher than that in the $6-8$ years age group $(\mathrm{OR}=1.28,95 \% \mathrm{CI}=1.08,1.53, p$ value $=0.005)$. Anaemic children were twice more likely to carry asymptomatic infections $(\mathrm{OR}=2.01,95 \% \mathrm{CI}=1.77,2.51, p$ value $<0.001)$ than the non-anaemic children and stunted growth increased the odds of carrying asymptomatic parasites by 

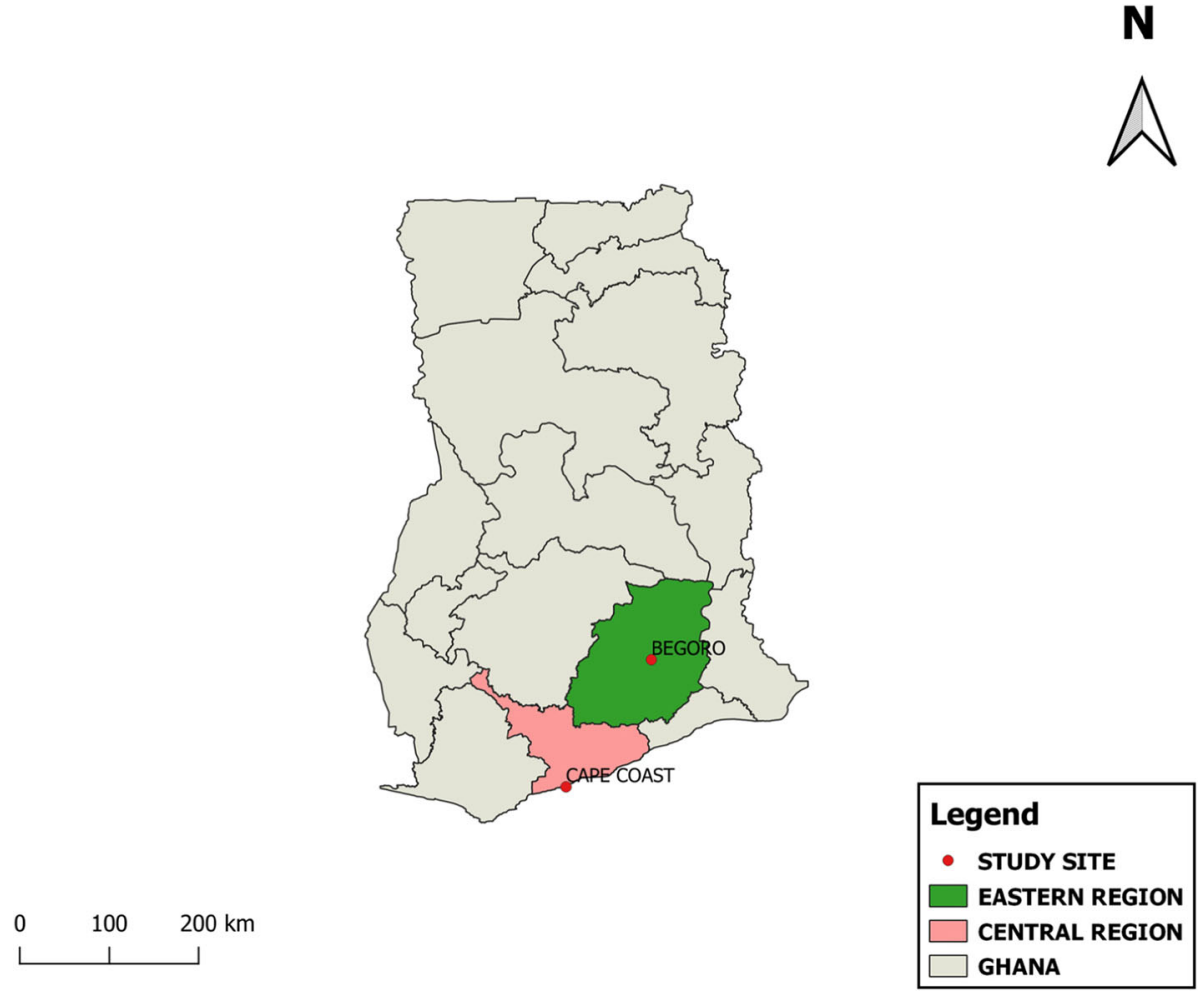

Fig. 1 Map of Ghana showing the location of the two study sites considered in the study. Begorois considered a forest ecological zone where malaria is hyperendemic and has a high transmission intensity. Cape Coast, is considered a coastal savanna zone where malaria is also hyperendemic, but it has a low to moderate transmission intensity

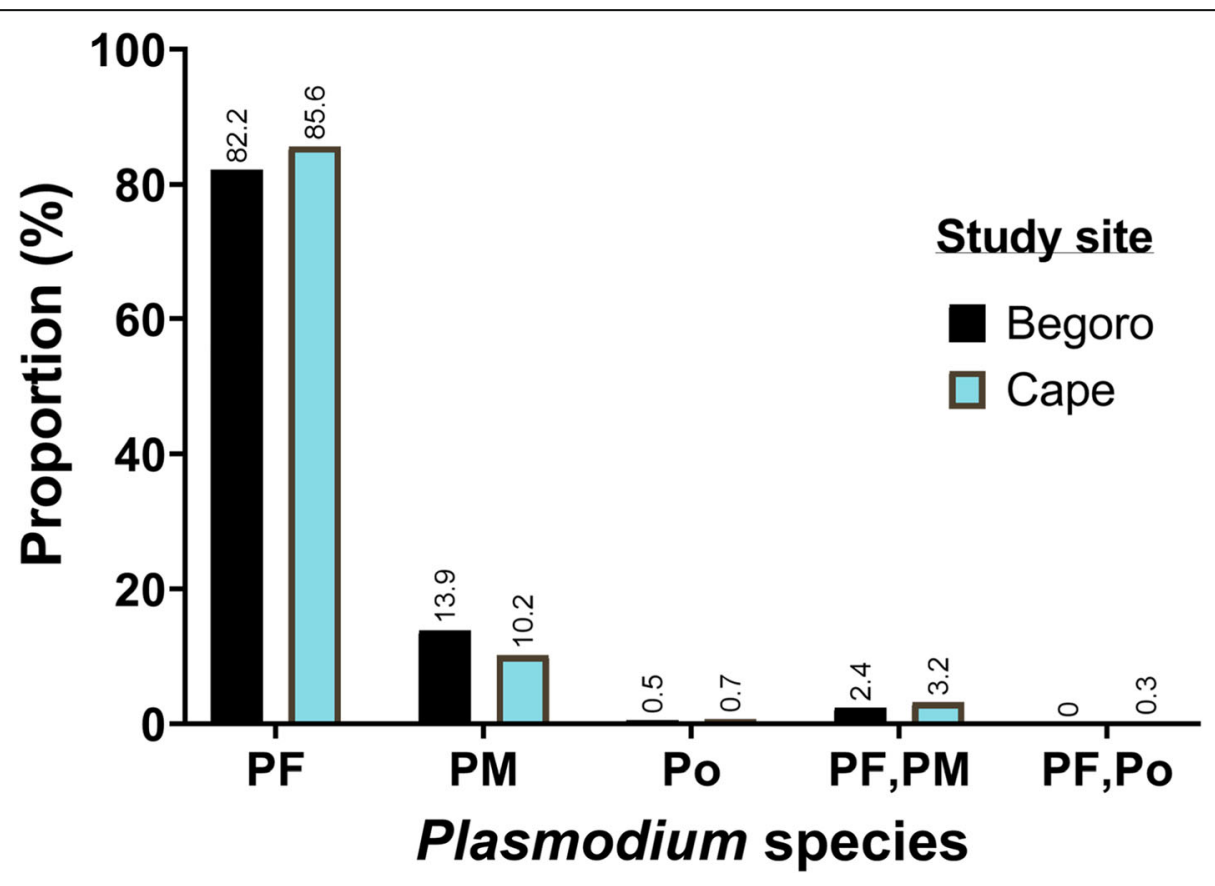

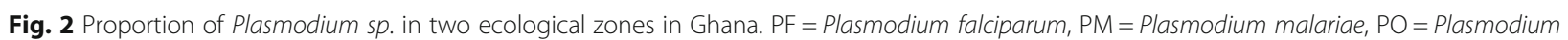
ovale, PF, PM = Plasmodium falciparum and malariae mixed infection, and PF, PO = Plasmodium falciparum and ovale mix infection 
Table 2 Factors associated with asymptomatic malaria

\begin{tabular}{|c|c|c|c|c|c|}
\hline \multirow[t]{3}{*}{ Parameter } & \multicolumn{4}{|c|}{ Asymptomatic malaria } & \multirow{3}{*}{$\begin{array}{l}p \\
\text { value }\end{array}$} \\
\hline & \multicolumn{2}{|l|}{ No } & \multicolumn{2}{|l|}{ Yes } & \\
\hline & $\mathbf{N}$ & $\%$ & $\mathrm{~N}$ & $\%$ & \\
\hline Gender & & & & & 0.001 \\
\hline Male & 1669 & 72.5 & 633 & 27.5 & \\
\hline Female & 1986 & 76.7 & 603 & 23.3 & \\
\hline Age group (years) & & & & & 0.019 \\
\hline 6 to 8 & 962 & 77.2 & 284 & 22.8 & \\
\hline 9 to 11 & 1396 & 75.0 & 466 & 25.0 & \\
\hline 12 to 14 & 1293 & 72.7 & 485 & 27.3 & \\
\hline Anaemia & & & & & $<0.001$ \\
\hline Non anaemic $(\geq 11)$ & 3193 & 76.8 & 965 & 23.2 & \\
\hline Anaemic $(<11)$ & 414 & 61.7 & 257 & 38.3 & \\
\hline Stunted growth & & & & & $<0.001$ \\
\hline Normal & 3295 & 75.8 & 1053 & 24.2 & \\
\hline Stunted & 361 & 66.2 & 184 & 33.8 & \\
\hline \multicolumn{6}{|l|}{ Study site } \\
\hline Begoro & 1758 & 73.4 & 636 & 26.6 & 0.04 \\
\hline Cape Coast & 1898 & 76.0 & 600 & 24.0 & \\
\hline
\end{tabular}

$46 \%(\mathrm{OR}=1.46,95 \% \mathrm{CI}=1.19,1.80, p$ value $<0.001)$. In addition, the study showed an increased odd of $26 \%$ asymptomatic carriage in Begoro (forest ecological zone) compared to Cape Coast (in the coastal savanna zone) after adjusting for age, sex, anaemia and stunted growth $(\mathrm{OR}=1.26, \quad 95 \% \quad \mathrm{CI}=1.10, \quad 1.44, \quad p \quad$ value $=0.001)$ (Table 3).

\section{Discussion}

With the clarion call for malaria elimination, attention has been drawn to the asymptomatic reservoir of infection as it significantly contributes to Plasmodium transmission. Thus, recent epidemiological studies in most malaria-endemic countries are not only focusing on symptomatic malaria for disease morbidity and mortality rates but also the asymptomatic infection rate to fully define the disease burden during malaria control and elimination interventions.
Our repeated cross-sectional surveys estimated the prevalence of the asymptomatic infections in catchment areas of two ecological zones in Ghana and also identified associated risk factors of asymptomatic malaria. The study revealed a high asymptomatic burden $(\sim 20 \%)$ in the two catchment areas studied, where most of the infections were $P$. falciparum. A few infections were $(P$. malariae, $P$. ovale, with mixed infection $P$. falciparum + P. malariae and P. falciparum $+P$. ovale). As expected, asymptomatic malaria was higher in Begoro, within the forest ecological niche compared to Cape Coast in the coastal region of Ghana and was associated with age, gender, anaemia and stunted growth in school children. The outcomes of this study highlight the need to expand control interventions and educational campaigns for asymptomatic malaria in Ghana with particular focus on males and older children.

The variation in asymptomatic carriage in these different ecological zones is consistent with transmission intensity in these two sites. The increased odds of asymptomatic malaria in the forest ecological zone may be due to more favorable climatic conditions such as temperature, abundant rainfall and the vegetative cover, resulting in an abundance of breeding sites for the mosquito vector in these areas. These variations observed in transmission between communities reflect the importance of micro-ecological factors and transmission in the areas studied [24]. The bulk of malaria cases in subSaharan Africa are caused by Plasmodium falciparum, with other Plasmodium species having a low but underestimated prevalence [1, 25]. The distribution of Plasmodium species in this study is consistent with other studies conducted in Ghana. P. falciparum is the most common malaria-causing species in Ghana, followed by P. malariae and P. ovale [25-27].

The prevalence of asymptomatic infections among children was more predominant in males than females. This disparity may come as a result of gender roles with regards to division of labour, hormonal or host genetic factors [28, 29], and behavioral factors like leisure activities and sleeping patterns [30]. Males tend to stay late outdoors and without proper protective clothing and

Table 3 Some risk factors associated with asymptomatic malaria

\begin{tabular}{|c|c|c|c|c|c|}
\hline \multicolumn{2}{|l|}{ Parameter } & \multicolumn{4}{|c|}{ Asymptomatic malaria } \\
\hline & Exposed group & $\begin{array}{l}\text { Unadjusted OR } \\
(95 \% \mathrm{Cl})\end{array}$ & $p$ value & $\begin{array}{l}\text { Adjusted OR } \\
(95 \% \mathrm{Cl})\end{array}$ & $p$ value \\
\hline Gender & Males & $1.24(1.10,1.42)$ & 0.001 & $1.18(1.03,1.35)$ & 0.015 \\
\hline \multirow[t]{2}{*}{ Age group (years) } & 9 to 11 & $1.13(0.96,1.34)$ & 0.154 & $1.11(0.93,1.32)$ & 0.2235 \\
\hline & 12 to 14 & $1.27(1.07,1.50)$ & 0.005 & $1.28(1.08,1.53)$ & 0.005 \\
\hline Anaemia & Anaemic & $2.05(1.73,2.44)$ & $<0.0001$ & $2.01(1.77,2.51)$ & $<0.001$ \\
\hline Stunted growth & Stunted & $1.59(1.32,1.93)$ & $<0.0001$ & $1.46(1.19,1.80)$ & $<0.001$ \\
\hline Study site & Begoro & $1.14(1.01,1.30)$ & 0.04 & $1.26(1.10,1.44)$ & 0.001 \\
\hline
\end{tabular}


they also have the tendency to sleep outdoors or not sleep under a mosquito net. It has been suggested that males usually have lower immune response than females [31]. The immunological differences between males and females, linked to circulating steroid hormones such as testosterone, oestradiol, and progesterone may explain the increased parasitism in males [31]. Not only do host hormones influence infection responses, but parasites in their hosts can also generate and modify hormone concentrations [32]. Some of these gender differences that affect disease outcomes includes access to immunization, nutritional status, access to, and use of preventive and curative health care, including differences in the speed with which males and females get treatment outside the home [30]. Understanding how gendered patterns of behavior influence exposure to mosquitoes can therefore assist in developing more-effective recommendations for preventing malaria infection especially in males.

In this study, children aged between 12 and 14 years were $21 \%$ more asymptomatic than children aged between 6 and 8 years. This was consistent with findings from other studies conducted in Ghana [33-35]. Age has been shown to be associated with malaria in general and studies have reported its association with asymptomatic malaria carriage [34]. An increase in age is positively associated with protective immunity to malaria in endemic settings where older children and adults have acquired partial immunity and are more likely to carry asymptomatic infections [34, 36].

Our study recorded a doubled risk of anaemia in children who had asymptomatic infections. Malariaassociated anaemia has been well documented, however, few studies have looked at the impact of asymptomatic malaria on anaemia in healthy children in schools. In general, malaria contributes to the loss of iron from lysed cells through excretion, impairment of intestinal absorption of ingested iron, the release of storage iron from hepatocytes, and recycling of iron that is derived from phagocytosis of senescent or parasitized erythrocytes by macrophages [37]. However, asymptomatic lower-density parasitemia may also contribute to anaemia, particularly if the parasitemia persists for prolonged periods due to lack of, or ineffective treatment [38, 39]. In addition, school children living in the Cape coast catchment area were more anaemic than their counterparts living in Begoro. Although our study was not designed to obtain information on diet, the anecdotal evidence indicates that the vegetation of Begoro allows for an abundant propagation of iron rich green leafy vegetables as staple for the community including our study catchment area in comparison with Cape Coast where the vegetation is mostly mangrove with salty patches.
Our study revealed that stunting was associated with asymptomatic malaria though a similar study conducted in another forest region of Ghana did not show an association between stunting and asymptomatic malaria [40]. The inconsistency in the results may be due to smaller sample size in the other study. Evidence of an association between malaria risk and anthropometric indicators such as stunting remains inconclusive [41]. While some studies have reported that stunting is associated with a higher risk of asymptomatic malaria as reported in this study [42, $43]$, others have suggested a protective effect [20, $44-$ 47]. For instance, Mitangala and colleagues in 2013 showed that severely stunted children were at a lower risk of high-level malaria [46]. Some studies also suggest no association between anthropometric indicators and asymptomatic malaria risk [40, 48, 49]. How malnutrition influences malaria morbidity and mortality is debatable. Some studies suggest that malnourished children seem to be more susceptible to malaria parasite carriage because of decreased immune system functioning [50]. This complex relationship may be influenced by confounders like socio-economic factors such as poverty, level of literacy of parent/guardian, common diet of community etc. [51].

This study had a few limitations. The study might have under-reported the prevalence of asymptomatic malaria because microscopic detection of parasites as used in the study has low sensitivity compared to polymerase chain reaction (PCR), although it is the gold standard for diagnosing malaria in endemic countries. Evidence of underreporting of malaria cases by microscopy has been shown [52, 53] compared to PCR. Microscopy reported a false negative diagnosis of $19.4 \%$ [52]. Also, the study did not consider household factors and the use of insecticide treated bed nets, which are also risk factors of malaria.

\section{Conclusion}

The prevalence of asymptomatic malaria was high in both study sites in Ghana. Asymptomatic malaria among the school children was age-dependent with a higher risk in male children. A significant association was indicated between asymptomatic malaria and the risk of anaemia and stunting. Thus, malaria control programs should also focus on asymptomatic malaria as a means to monitor the impact of control interventions and to reduce malaria morbidity and mortality.

\section{Abbreviations}

GCP: Good Clinical Practice; HAZ: Height-for-Age Z scores; OPD: Out-Patient Department; NMPC: National Malaria Control Program; PF: Plasmodium falciparum; PM: Plasmodium malariae; PO: Plasmodium ovale; WHO: World Health Organization 


\section{Acknowledgments}

The authors will like to thanks the study participants, parents/guardians, staff and management of the school that participated in the study from Begoro and Cape Coast.

\section{Authors' contributions}

BAM implemented the study and wrote the first draft of the manuscript. AG and BKA conceptualized the idea, were involved in the design, implementation and writing of the manuscript. JLMH, MO, EOA, were involved in data collection and review of the manuscript. The author(s) read and approved the final manuscript.

\section{Funding}

The study was funded by the National Institute of Health grant number R01A1099527.

\section{Availability of data and materials}

The dataset used and/or analysed during the current study is available from the corresponding author on reasonable request.

\section{Declarations}

\section{Ethics approval and consent to participate}

The protocol was approved by the ethics review board of Noguchi Memorial Institute for Medical Research, University of Ghana (IRB approval no. 056/1213). Written informed consent was obtained from the parents or guardians of all children before enrollment. Additionally, children aged 12 years to 14 years gave their assent before enrollment. The study was conducted following the latest Declaration of Helsinki and Good Clinical Practice (GCP).

\section{Consent for publication}

Not applicable.

\section{Competing interests}

Authors declare no conflicting interest.

Received: 11 January 2021 Accepted: 29 August 2021

\section{Published online: 17 September 2021}

\section{References}

1. WHO. World malaria report 2019. 2019a. Retrieved from https://www.who. int/publications-detail/world-malaria-report-2019.

2. United Nations Children's Fund. UNICEF report: improving child nutrition: the achievable imperative for global progress. 2013. Retrieved from.

3. Brooker SJ, Clarke S, Fernando D, Gitonga CW, Nankabirwa J, Schellenberg D, Greenwood B. Malaria in middle childhood and adolescence. Disease Control Priorities, (Volume 8): Child and Adolescent Health and Development, 1982. 2017.

4. Kimbi HK, Awah NW, Ndamukong KJ, Mbuh JV. Malaria infection and its consequences in school children. East Afr Med J. 2005;82(2):92-7. https:// doi.org/10.4314/eamj.v82i2.9261.

5. Nankabirwa J, Brooker SJ, Clarke SE, Fernando D, Gitonga CW, Schellenberg $D$, et al. Malaria in school-age children in Africa: an increasingly important challenge. Tropical Med Int Health. 2014;19(11):1294-309. https://doi.org/1 $0.1111 /$ tmi. 12374 .

6. NMCP. National malaria program annual report 2017. 2017. Retrieved from http://www.ccmghana.net/index.php/strategic-plans-reports\%3Fdownloa d\%3D200:nmcp-2017.

7. Laishram DD, Sutton PL, Nanda N, Sharma VL, Sobti RC, Carlton JM, et al. The complexities of malaria disease manifestations with a focus on asymptomatic malaria. Malar J. 2012;11(1):29. https://doi.org/10.1186/1475-2 875-11-29.

8. Bousema JT, Gouagna LC, Drakeley CJ, Meutstege AM, Okech BA, Akim IN, et al. Plasmodium falciparum gametocyte carriage in asymptomatic children in western Kenya. Malar J. 2004;3(1):18. https://doi.org/10.1186/1475-2 875-3-18.

9. Gouagna LC, Ferguson HM, Okech BA, Killeen GF, Kabiru EW, Beier JC, et al. Plasmodium falciparum malaria disease manifestations in humans and transmission to Anopheles gambiae: a field study in Western Kenya. Parasitology. 2004;128(Pt 3):235-43. https://doi.org/10.1017/s0031182003 00444x.
10. Lennon SE, Miranda A, Henao J, Vallejo AF, Perez J, Alvarez A, et al. Malaria elimination challenges in Mesoamerica: evidence of submicroscopic malaria reservoirs in Guatemala. Malar J. 2016;15(1):441. https://doi.org/10.1186/s12 936-016-1500-6.

11. Lin JT, Saunders DL, Meshnick SR. The role of submicroscopic parasitemia in malaria transmission: what is the evidence? Trends Parasitol. 2014;30(4):18390. https://doi.org/10.1016/j.pt.2014.02.004.

12. Stresman GH, Baidjoe AY, Stevenson J, Grignard L, Odongo W, Owaga C, et al. Focal screening to identify the subpatent parasite reservoir in an area of low and heterogeneous transmission in the Kenya highlands. J Infect Dis. 2015;212(11):1768-77. https://doi.org/10.1093/infdis/jiv302.

13. Sturrock HJ, Hsiang MS, Cohen JM, Smith DL, Greenhouse B, Bousema T, et al. Targeting asymptomatic malaria infections: active surveillance in control and elimination. PLoS Med. 2013;10(6):e1001467. https://doi.org/1 0.1371/journal.pmed.1001467.

14. Tadesse FG, Slater HC, Chali W, Teelen K, Lanke K, Belachew M, et al. The relative contribution of symptomatic and asymptomatic plasmodium vivax and plasmodium falciparum infections to the infectious reservoir in a lowendemic setting in Ethiopia. Clin Infect Dis. 2018;66(12):1883-91. https://doi. org/10.1093/cid/cix1123.

15. Zoghi S, Mehrizi AA, Raeisi A, Haghdoost AA, Turki H, Safari R, et al. Survey for asymptomatic malaria cases in low transmission settings of Iran under elimination programme. Malar J. 2012;11(1):126. https://doi.org/10.1186/14 75-2875-11-126.

16. Alves FP, Gil LHS, Marrelli MT, Ribolla PE, Camargo EP, Da Silva LHP. Asymptomatic carriers of plasmodium spp. as infection source for malaria vector mosquitoes in the Brazilian Amazon. J Med Entomol. 2005;42(5):777-9. https://doi.org/10.1603/0022-2585(2005)042[0777:A COPSA]2.0.CO;2.

17. Ouedraogo AL, Goncalves BP, Gneme A, Wenger EA, Guelbeogo MW, Ouedraogo A, et al. Dynamics of the human infectious reservoir for malaria determined by mosquito feeding assays and ultrasensitive malaria diagnosis in Burkina Faso. J Infect Dis. 2016;213(1):90-9. https://doi.org/10.1093/infdis/ jiv370.

18. Schneider P, Bousema JT, Gouagna LC, Otieno S, van de Vegte-Bolmer M, Omar SA, et al. Submicroscopic plasmodium falciparum gametocyte densities frequently result in mosquito infection. Am J Trop Med Hyg. 2007; 76(3):470-4 Retrieved from http://www.ncbi.nlm.nih.gov/pubmed/17360869.

19. Rovira-Vallbona E, Contreras-Mancilla JJ, Ramirez R, Guzmán-Guzmán M, Carrasco-Escobar G, Llanos-Cuentas A, et al. Predominance of asymptomatic and sub-microscopic infections characterizes the plasmodium gametocyte reservoir in the Peruvian Amazon. PLoS Negl Trop Dis. 2017;11(7):e0005674. https://doi.org/10.1371/journal.pntd.0005674.

20. Goyal S. Protein energy malnutrition and cerebral malaria. J Trop Pediatr. 1991;37(3):143-4.

21. Thuma PE, Van Dijk J, Bucala R, Debebe Z, Nekhai S, Kuddo T, et al. Distinct clinical and immunologic profiles in severe malarial anemia and cerebral malaria in Zambia. J Infect Dis. 2011;203(2):211-9. https://doi.org/10.1093/ infdis/jiq041.

22. Kastenmuller K, Espinosa DA, Trager L, Stoyanov C, Salazar AM, Pokalwar S, et al. Full-length plasmodium falciparum circumsporozoite protein administered with long-chain poly(I.C) or the toll-like receptor 4 agonist glucopyranosyl lipid adjuvant-stable emulsion elicits potent antibody and CD4+ T cell immunity and protection in mice. Infect Immun. 2013;81(3): 789-800. https://doi.org/10.1128/IAl.01108-12.

23. Mensah BA, Aydemir O, Myers-Hansen JL, Opoku M, Hathaway NJ, Marsh PW, et al. Antimalarial drug resistance profiling of plasmodium falciparum infections in Ghana using molecular inversion probes and next generation sequencing. Antimicrob Agents Chemother. 2020;64(4). https://doi.org/1 0.1128/AAC.01423-19.

24. Dery DB, Brown C, Asante KP, Adams M, Dosoo D, Amenga-Etego S, et al. Patterns and seasonality of malaria transmission in the forest-savannah transitional zones of Ghana. Malar J. 2010;9(1):314. https://doi.org/10.1186/14 75-2875-9-314.

25. Amoah LE, Donu D, Abuaku B, Ahorlu C, Arhinful D, Afari E, et al. Probing the composition of plasmodium species contained in malaria infections in the eastern region of Ghana. BMC Public Health. 2019;19(1):1-11. https://doi. org/10.1186/s12889-019-7989-1.

26. Owusu ED, Brown CA, Grobusch MP, Mens P. Prevalence of plasmodium falciparum and non-P. falciparum infections in a highland district in Ghana, and the influence of HIV and sickle cell disease. Malar J. 2017;16(1):1-8. 
27. Williams O, Meek S. Malaria: country profiles. London: Department of international development; 2011.

28. Pathak S, Rege M, Gogtay NJ, Aigal U, Sharma SK, Valecha N, et al. Age-dependent sex bias in clinical malarial disease in hypoendemic regions. PLoS One. 2012;7(4):e35592. https://doi.org/10.1371/journal. pone.0035592.

29. van Eijk AM, Sutton PL, Ramanathapuram L, Sullivan SA, Kanagaraj D, Priya GSL, et al. The burden of submicroscopic and asymptomatic malaria in India revealed from epidemiology studies at three varied transmission sites in India. Sci Rep. 2019;9(1):17095. https://doi.org/10.1038/s41598-019-53386-w.

30. Stukel TA, Glynn RJ, Fisher ES, Sharp SM, Lu-Yao G, Wennberg JE. Standardized rates of recurrent outcomes. Stat Med. 1994;13(17):1781-91. https://doi.org/10.1002/sim.4780131709.

31. Klein SL. Hormonal and immunological mechanisms mediating sex differences in parasite infection. Parasite Immunol. 2004;26(6-7):247-64. https://doi.org/10.1111/j.0141-9838.2004.00710.x.

32. Klein PW, Easterbrook JD, Lalime EN, Klein SL. Estrogen and progesterone affect responses to malaria infection in female C57BL/6 mice. Gend Med. 2008;5(4):423-33. https://doi.org/10.1016/j.genm.2008.10.001.

33. Danquah I, Ziniel P, Eggelte TA, Ehrhardt S, Mockenhaupt FP. Influence of haemoglobins $S$ and $C$ on predominantly asymptomatic Plasmodium infections in northern Ghana. Trans R Soc Trop Med Hyg. 2010;104(11):7139. https://doi.org/10.1016/j.trstmh.2010.08.001.

34. Kanwugu ON, Helegbe GK, Aryee PA, Abdul-Karim A, Anaba F, Ziblim Z, et al. Prevalence of asymptomatic malaria among children in the Tamale Metropolis: how does the PfHRP2 CareStart'TM RDT perform against microscopy? J Trop Med. 2019;2019:6457628-7. https://doi.org/10.1155/201 9/6457628.

35. Owusu ED, Buabeng V, Dadzie S, Brown CA, Grobusch MP, Mens PJM j. Characteristics of asymptomatic Plasmodium spp. parasitaemia in KwahuMpraeso, a malaria endemic mountainous district in Ghana, West Africa. Malar J. 2016;15(1):38.

36. Zaw MT, Thant M, Hlaing TM, Aung NZ, Thu M, Phumchuea K, et al. Asymptomatic and sub-microscopic malaria infection in Kayah State, eastern Myanmar. Malar J. 2017;16(1):138.

37. Verhoef H. Asymptomatic malaria in the etiology of iron deficiency anemia: a malariologist's viewpoint. Am J Clin Nutr. 2010;92(6):1285-6. https://doi. org/10.3945/ajcn.110.006700.

38. Luxemburger C, Nosten F, Kyle DE, Kiricharoen L, Chongsuphajaisiddhi T, White NJ. Clinical features cannot predict a diagnosis of malaria or differentiate the infecting species in children living in an area of low transmission. Trans R Soc Trop Med Hyg. 1998;92(1):45-9. https://doi.org/1 0.1016/s0035-9203(98)90950-6.

39. Sumbele IU, Kimbi HK, Ndamukong-Nyanga JL, Nweboh M, Anchang-Kimbi JK, Lum E, et al. Malarial anaemia and anaemia severity in apparently healthy primary school children in urban and rural settings in the Mount Cameroon area: cross sectional survey. PLoS One. 2015a;10(4):e0123549. https://doi.org/10.1371/journal.pone.0123549.

40. Crookston BT, Alder SC, Boakye I, Merrill RM, Amuasi JH, Porucznik CA, et al. Exploring the relationship between chronic undernutrition and asymptomatic malaria in Ghanaian children. Malar J. 2010a;9(1). https://doi. org/10.1186/1475-2875-9-39 http://europepmc.org/abstract/MED/20122258 http://www.biomedcentral.com/content/pdf/1475-2875-9-39.pdf.

41. Das D, Grais RF, Okiro EA, Stepniewska K, Mansoor R, van der Kam S, et al. Complex interactions between malaria and malnutrition: a systematic literature review. BMC Med. 2018;16(1):186. https://doi.org/10.1186/s12916018-1177-5.

42. Akiyama T, Pongvongsa T, Phrommala S, Taniguchi T, Inamine Y, Takeuchi R, et al. Asymptomatic malaria, growth status, and anaemia among children in Lao People's Democratic Republic: a cross-sectional study. Malar J. 2016; 15(1):499. https://doi.org/10.1186/s12936-016-1548-3.

43. Gari T, Loha E, Deressa W, Solomon T, Lindtjørn B. Malaria increased the risk of stunting and wasting among young children in Ethiopia: results of a cohort study. PLoS One. 2018;13(1):e0190983. https://doi.org/10.1371/journa I.pone.0190983.

44. Ferreira E d A, Alexandre MA, Salinas JL, de Siqueira AM, Benzecry SG, de Lacerda MVG, et al. Association between anthropometry-based nutritional status and malaria: a systematic review of observational studies. Malar J. 2015;14(1):346. https://doi.org/10.1186/s12936-015-0870-5.

45. Genton B, Al-Yaman F, Ginny M, Taraika J, Alpers MP. Relation of anthropometry to malaria morbidity and immunity in Papua New Guinean children. Am J Clin Nutr. 1998;68(3):734-41. https://doi.org/10.1093/ajcn/ 68.3.734.

46. Mitangala P, D'Alessandro U, Donnen P, Hennart P, Porignon D, Balaluka GB, et al. Infection palustre et état nutritionnel: résultats d'une cohorte d'enfants âgés de 6 à 59 mois au Kivu en République démocratique du Congo. Rev Epidemiol Sante Publique. 2013a;61(2):111-20. https://doi.org/10.1016/j. respe.2012.06.404.

47. Mzumara B, Bwembya P, Halwiindi H, Mugode R, Banda J. Factors associated with stunting among children below five years of age in Zambia: evidence from the 2014 Zambia demographic and health survey. BMC Nutrition. 2018;4(1):51. https://doi.org/10.1186/s40795-018-0260-9.

48. Awuah RB, Asante PY, Sakyi L, Biney AAE, Kushitor MK, Agyei F, et al. Factors associated with treatment-seeking for malaria in urban poor communities in Accra, Ghana. Malar J. 2018a;17(1):168. https://doi.org/10.1186/s12936-01 8-2311-8.

49. Sumbele IUN, Bopda OSM, Kimbi HK, Ning TR, Nkuo-Akenji T. Nutritional status of children in a malaria meso endemic area: cross sectional study on prevalence, intensity, predictors, influence on malaria parasitaemia and anaemia severity. BMC Public Health. 2015b;15(1):1099. https://doi.org/10.11 86/s12889-015-2462-2

50. Bowman NM, Congdon S, Mvalo T, Patel JC, Escamilla V, Emch M, et al. Comparative population structure of plasmodium falciparum circumsporozoite protein NANP repeat lengths in Lilongwe, Malawi. Sci Rep. 2013;3(1):1990. https://doi.org/10.1038/srep01990.

51. Deen J, Walraven G, Von Seidlein L. Increased risk for malaria in chronically malnourished children under 5 years of age in rural Gambia. J Trop Pediatr. 2002;48(2):78-83. https://doi.org/10.1093/tropej/48.2.78.

52. Berzosa P, de Lucio A, Romay-Barja M, Herrador Z, González V, García L, et al. Comparison of three diagnostic methods (microscopy, RDT, and PCR) for the detection of malaria parasites in representative samples from Equatorial Guinea. Malar J. 2018;17(1):1-12. https://doi.org/10.1186/s12936018-2481-4.

53. Mfuh KO, Achonduh-Atijegbe OA, Bekindaka ON, Esemu LF, Mbakop CD, Gandhi K, et al. A comparison of thick-film microscopy, rapid diagnostic test, and polymerase chain reaction for accurate diagnosis of plasmodium falciparum malaria. Malar J. 2019;18(1):1-8. https://doi.org/10.1186/s12936-01 9-2711-4.

\section{Publisher's Note}

Springer Nature remains neutral with regard to jurisdictional claims in published maps and institutional affiliations.

Ready to submit your research? Choose BMC and benefit from:

- fast, convenient online submission

- thorough peer review by experienced researchers in your field

- rapid publication on acceptance

- support for research data, including large and complex data types

- gold Open Access which fosters wider collaboration and increased citations

- maximum visibility for your research: over $100 \mathrm{M}$ website views per year

At $\mathrm{BMC}$, research is always in progress.

Learn more biomedcentral.com/submissions 